\title{
Choledochoduodenal fistula: an unusual case of pneumobilia
}

\author{
Raphael Fedidat, ${ }^{1}$ Wajdi Safadi, ${ }^{1,2}$ Igor Waksman, ${ }^{1}$ Amram Hadary ${ }^{1}$
}

'Department of Surgery, Ziv Hospital Affiliated to the Faculty of Medicine in the Galilee, Bar Ilan University, Safed, Israel

${ }^{2}$ Golan Polyclinic, Golan Heights, Israel

\section{Correspondence to}

Dr Wajdi Safadi,

golanpolyclinic@gmail.com

Accepted 25 September 2014

\section{SUMMARY}

Pneumobilia is the finding of air in the biliary tree. Most cases are iatrogenic in origin, especially after sphincterotomy and after hepaticojejunostomy or choledochojejunostomy. In patients without such history, the presence of pneumobilia needs further investigation. Most patients are likely to have an enterobiliary fistula. Although patients may be asymptomatic, possible complications include gallstone ileus, Bouveret syndrome or recurrent episodes of cholangitis. We present a case of a 38-year-old man presenting with obstructive jaundice and pneumobilia in whom choledochoduodenal fistula was diagnosed at endoscopic retrograde cholangiography. A description of different types of choledochoduodenal fistulas and management recommendations are also provided.

\section{BACKGROUND}

Enterobiliary fistula was first described by Bartholin in $1654 .^{1}$ Sixty-eight per cent of cases occur between the gallbladder wall and duodenum. This may cause the well-known gallstone ileus and Bouveret syndromes. Only $8.6 \%$ of enterobiliary fistulas are of the choledochoduodenal type. ${ }^{2}$ This type of fistula may present with symptoms of peptic ulcer disease or as recurrent episodes of cholangitis. A high index of suspicion is needed for the correct diagnosis. Here we present a case of choledochoduodenal fistula in order to raise awareness of this rare cause of pneumobilia.

\section{CASE PRESENTATION}

A 38-year-old man, a new immigrant from Ethiopia, presented at our institution's emergency department with epigastric pain for 5 years and a 2-month history of nausea, vomiting and pale stool. He was otherwise healthy. This was his first presentation.

On physical examination, the patient was afebrile and mildly jaundiced. There was mild tenderness in the epigastrium.

Laboratory tests revealed leucocytosis of $11900 / \mu \mathrm{L}$ with $86 \%$ neutrophils and $C$ reactive protein of $183 \mathrm{mg} / \mathrm{L}$. Transaminases were slightly elevated (aspartate aminotransferase $62 \mathrm{IU} / \mathrm{L}$, alanine transaminase $125 \mathrm{IU} / \mathrm{L}$ ), total bilirubin at presentation was $4.4 \mathrm{mg} / \mathrm{dL}$ and direct bilirubin $2.2 \mathrm{mg} / \mathrm{dL}$, alkaline phosphatase $260 \mathrm{IU} / \mathrm{L} \quad \gamma$-glutamyl transpeptidase $239 \mathrm{IU} / \mathrm{L}$, amylase $45 \mathrm{IU} / \mathrm{L}$ and cancer antigen 19-9 was elevated at $140 \mathrm{U} / \mathrm{mL}$ (range $0-39$ ).

\section{To cite: Fedidat $\mathrm{R}$} Safadi W, Waksman I, et al. BMJ Case Rep Published online: [please include Day Month Year] doi:10.1136/ bcr-2014-206798

\section{INVESTIGATIONS}

Abdominal X-ray revealed air within the biliary tree (figure 1). On abdominal ultrasound there was

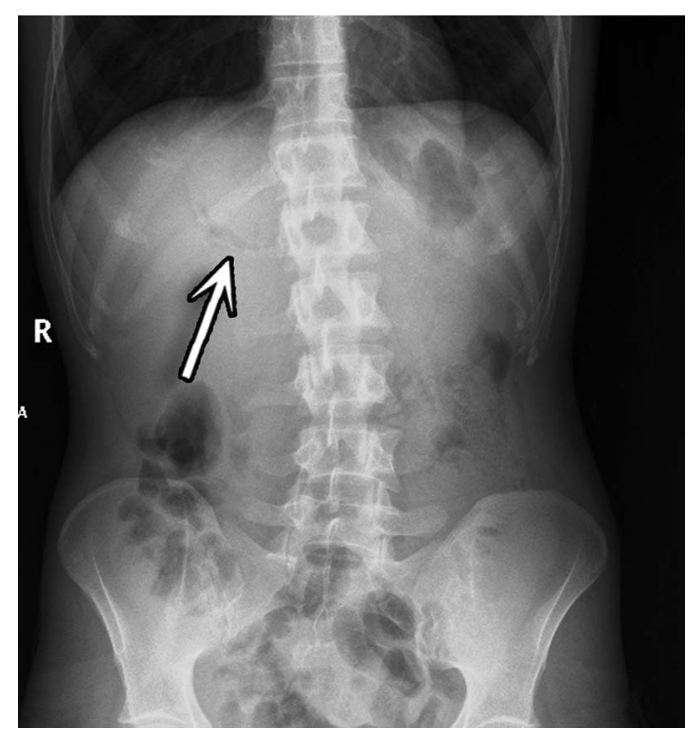

Figure 1 Plain abdominal X-ray showing air in biliary tree (white arrow).

thickening of the gallbladder wall and pericholecystic fluid, but no sludge or stones. The intrahepatic bile ducts were dilated and the common bile duct (CBD) measured $10 \mathrm{~mm}$ in width, raising suspicion of a distal obstruction. Pneumobilia was confirmed.

CT showed a $4 \mathrm{~cm}$ gallbladder with wall thickening and without cholelithiasis. The CBD was $14 \mathrm{~mm}$ wide with hyperdense material at its distal end (figure 2). The intrahepatic biliary tree was enlarged bilaterally with pneumobilia (figure 3). The pancreas was normal.

Although the cause of pneumobilia remained unclear, radiological findings suggested cholecystitis and choledocholithiasis.

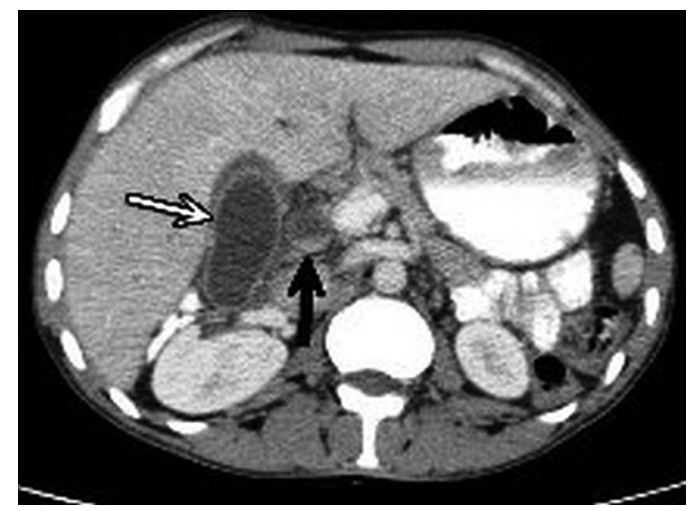

Figure 2 CT showing gallbladder with wall thickening (white arrow) and enlarged common bile duct with sludge (black arrow). 


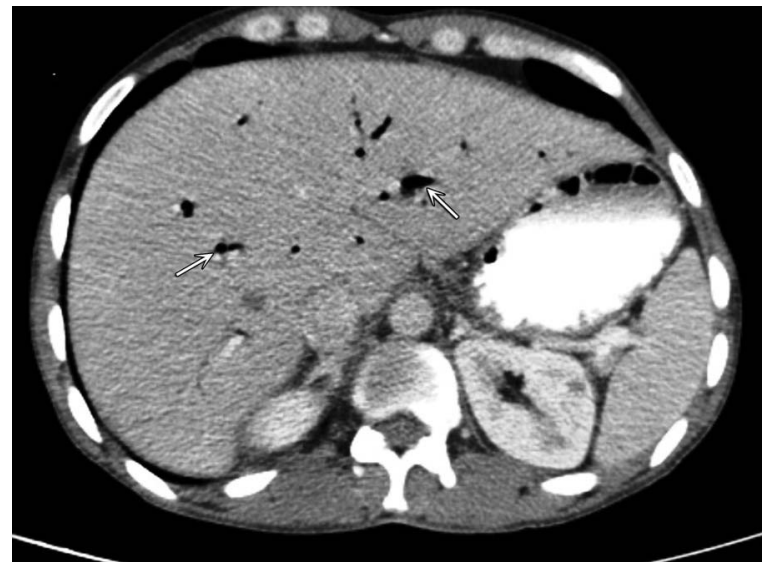

Figure 3 CT showing air within intrahepatic bile ducts (white arrows).

\section{DIFFERENTIAL DIAGNOSIS}

The most common cause of pneumobilia is iatrogenic-after endoscopic retrograde cholangiopancreatogram (ERCP) with or without sphincterotomy or after hepaticojejunostomy or choledochojejunostomy. Other cases include enterobiliary or bronchobiliary fistula, emphysematous cholecystitis or liver abscess, blunt abdominal trauma or cardiopulmonary resuscitation and congenital incompetence of the sphincter of Oddi.

\section{TREATMENT}

The patient was admitted for intravenous antibiotic therapy and an ERCP was planned to elucidate a diagnosis and relieve jaundice.

At ERCP the major duodenal papilla was normal in appearance but the injected contrast fluid returned to the duodenum via a suprapapillary choledochoduodenal fistula. After papillotomy, biliary sludge was extracted with a basket sweep.

\section{OUTCOME AND FOLLOW-UP}

After ERCP the patient's symptoms were relieved and liver function tests returned to normal. The patient was discharged. Ambulatory MR cholangiopancreatogram (MRCP) showed a normal CBD with no stones. There were no stones in the gallbladder. No fistula was seen. The decision was taken, therefore, to manage the patient conservatively. The patient remains asymptomatic after 1 year follow-up.

\section{DISCUSSION}

The gallbladder is in close apposition to its surrounding organs. The inferior surface of the fundus and the body of the gallbladder lies close to the transverse colon. The neck of the gallbladder and the cystic duct lie on the first part of the duodenum. The CBD descends in the free edge of lesser omentum behind the first

Table 1 Types of enterobiliary fistula ${ }^{2}$

\begin{tabular}{ll}
\hline Type of enterobiliary fistula & Percentage of cases \\
\hline Cholecystoduodenal & 68 \\
Cholecystocolonic & 13.6 \\
Choledochoduodenal & 8.6 \\
Cholecystogastric & 4.9 \\
Duodeno-left hepatic & 4.9 \\
\hline
\end{tabular}

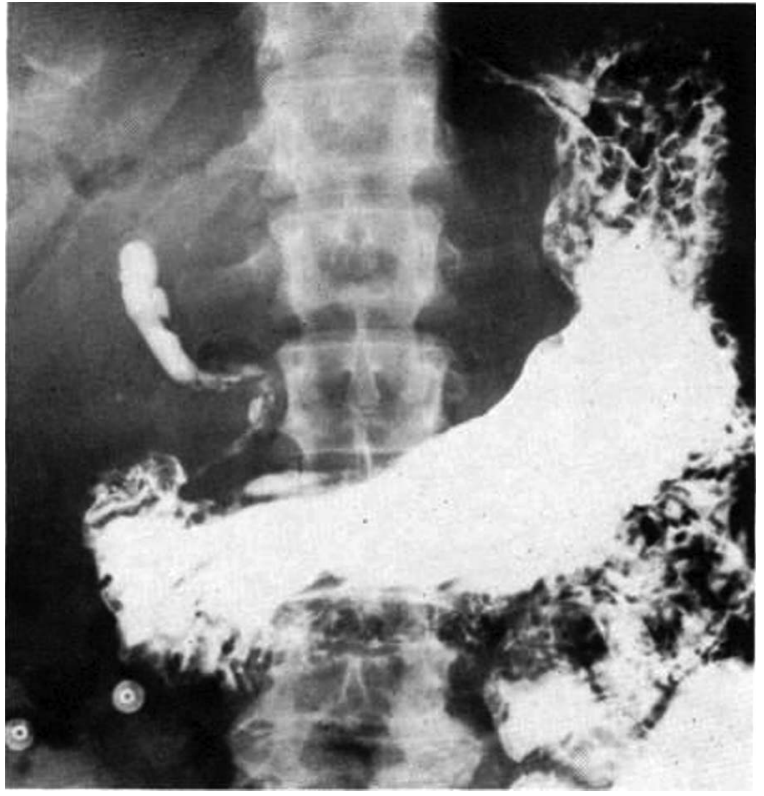

Figure 4 Barium swallow test demonstrating reflux of contrast into the common bile duct. Adapted from Hoppenstein et al. ${ }^{5}$

part of the duodenum, approximately $7 \mathrm{~cm}$ distal to the pylorus, and opens into the major duodenal papilla.

Of all the types of enterobiliary fistula, the most common is cholecystoduodenal (table 1).

This condition is generally caused by a stone impacted at the neck of the gallbladder with secondary pressure necrosis of the gallbladder wall and fistula formation into the first part of the duodenum.

Choledochoduodenal fistula (CDF) may occur at two distinct sites in the CBD, and is described in terms of two broad classes (proximal and distal). Since the pathological cause is different in each type, it is important to distinguish between them in order to manage treatment accordingly.

Proximal CDF, the most common type, occurs between the CBD and posterior wall of the duodenal bulb. In $80 \%$ of cases

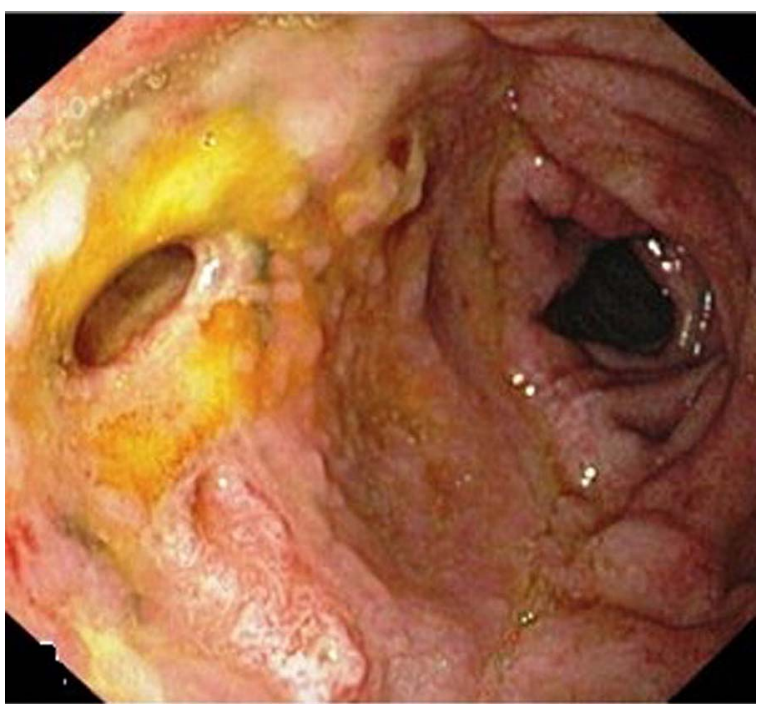

Figure 5 Gastroduodenoscopy showing ostium with bilious secretion entering through the posterior wall of the duodenal bulb. Adapted from Neumann et al. ${ }^{6}$ 


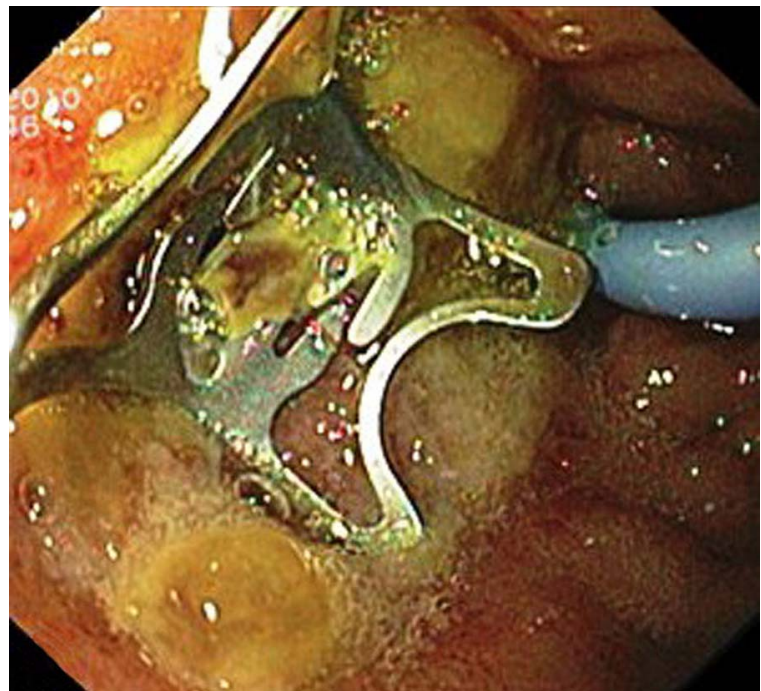

Figure 6 Endoscopic repair of a proximal choledochoduodenal fistula with an $11 \mathrm{~mm}$ over-the-scope clip. Adapted from Neumann et al. ${ }^{6}$

there is a history of long-standing dyspepsia and the pathophysiology is of acid-dependent duodenal ulceration and fistulation into the posteriorly located proximal CBD. Rarely, it can present as upper gastrointestinal bleeding, sometimes massive, because of ulceration and perforation into the gastroduodenal or superior pancreaticoduodenal artery. ${ }^{3} \mathrm{Kyle}^{4}$ described the sudden relief of dyspeptic symptoms after such fistula formation because of the alkalising property of bile relative to the hyperacid environment of the ulcer. Other causes are secondary to duodenal diverticulitis, paraduodenal abscess, trauma and carcinoma of the duodenum or bile duct. Barium swallow demonstrates reflux of contrast into the bile ducts (figure 4). ${ }^{5}$ The diagnosis is made at endoscopy when bile is seen entering through the posterior wall of the duodenal bulb. (figure 5). ${ }^{6}$ Ulcer treatment with a proton-pump inhibitor or a $\mathrm{H} 2$ antagonist is sufficient in the treatment of this type of fistula. ${ }^{7}$ For refractory cases, vagotomy with distal gastrectomy (antrectomy) and gastrojejunostomy with Billroth II reconstruction has been suggested, leaving the fistula intact. ${ }^{8}$ Closure of the fistula with a covered metal stent has been recently described ${ }^{9}$ (figure 6). ${ }^{6}$

Distal CDF occurs near the entrance of the distal CBD into the second part of the duodenum. Typically, in $90 \%$ of cases, the cause is an impacted stone in the distal $2 \mathrm{~cm}$ of the CBD, producing erosion of the $\mathrm{CBD}$ wall and fistulation into the descending
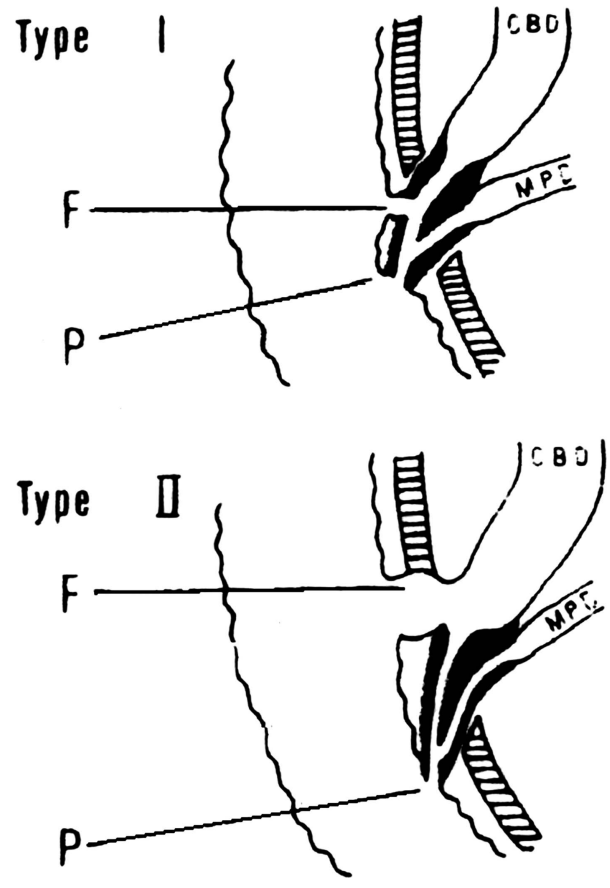

Figure 7 Ikeda classification of distal choledochoduodenal fistula. $C B D$, common bile duct; $M P D$, main pancreatic duct; $P$, papilla of vater; $\mathrm{F}$, fistula. ${ }^{11}$

duodenum. ${ }^{10}$ Other causes are ampullary carcinoma or cholangiocarcinoma of the distal CBD. Patients usually present with the classic triad of cholangitis: right-upper quadrant pain, fever and jaundice. Ikeda and Okada ${ }^{11}$ further classified distal CDF into type I and type II (figure 7). In type I the fistula arises on the longitudinal fold just adjacent to the papilla as a result of a small stone impacted at the intramural portion of the CBD. In type II, named suprapapillary distal CDF, as in our case, the fistula arises on the duodenal mucosa itself, proximal but adjacent to the duodenal fold. In this type of CDF, gallstones impacted are typically larger and impact in the extramural portion of CBD. Diagnosis of distal CDF is made at ERCP with back-flow of the injected contrast from the fistula itself (figure 8A). Treatment is typically carried out during ERCP with fistulotomy, extended sphincterotomy and extraction of stones ${ }^{12}$ (figure $8 \mathrm{~B}$ ). If not already performed, laparoscopic cholecystectomy should later be performed. For higher fistula within the distal CBD when fistulotomy is not safe, choledochojejunostomy is a surgical option. ${ }^{13}$
Figure 8 Photographs from endoscopic retrograde cholangiopancreatogram. (A) The ampulla of Vater with cannula in place. Contrast injected through the cannula flows back into the duodenum through the fistula tract. (B) After papillotomy, two large common bile duct stones being extracted into the duodenum using the papillotomy. Adapted from http://www.EndoAtlas. com, Atlanta South Gastroenterology.
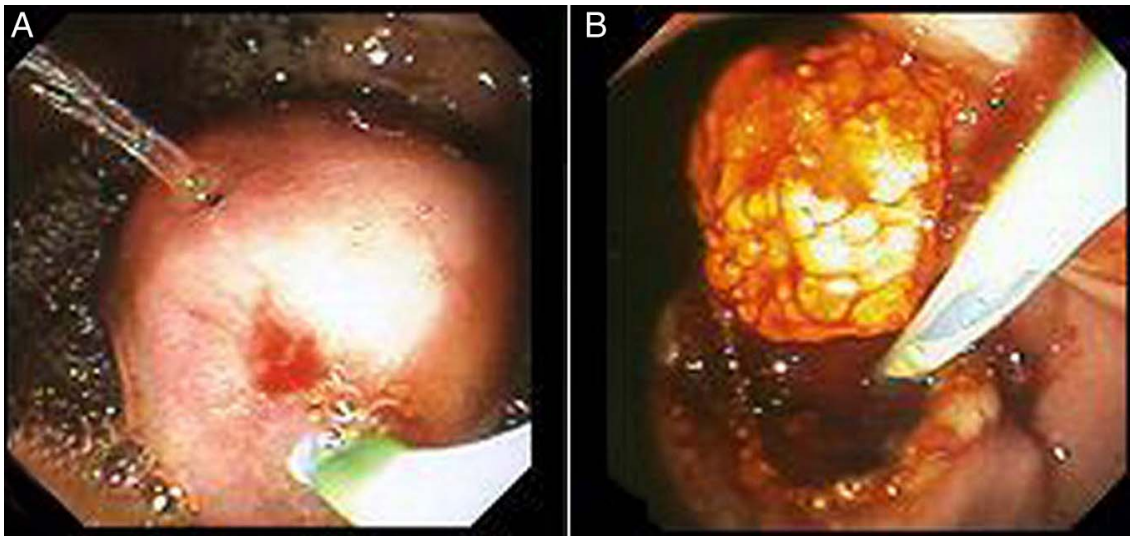


\section{Learning points}

- In patients with peptic ulcer disease and pneumobilia, one must consider the presence of a proximal choledochoduodenal fistula. Standard medical treatment of peptic ulcer disease will heal the fistula.

- Patients with recurrent episodes of cholangitis should be investigated for a distal choledochoduodenal fistula, and endoscopic retrograde cholangiopancreatogram performed for diagnosis and extended sphincterotomy.

- A high index of suspicion is needed for this relatively easy-to-treat condition.

\section{Competing interests None.}

Patient consent Obtained.

Provenance and peer review Not commissioned; externally peer reviewed.

\section{REFERENCES}

1 Eliason EL, Stevens LW. Spontaneous internal biliary fistulae. Am J Surg 1941;51:387.
2 Stagnitti F, Mongardini M, Schillaci F, et al. Spontaneous biliodigestive fistulae. The clinical consideration, surgical treatment and complications. $G$ Chir 2000;21:110-17.

3 Xeropotamos NS, Nousias VE, Vekris AD, et al. Choledochoduodenal fistula: an unusual complication of penetrated duodenal ulcer disease. Ann Gastroenterol 2004; 17:104-8

4 Kyle J. Choledochoduodenal fistula due to duodenal ulceration. $\mathrm{Br} J$ Surg 1958;46:124-7.

5 Hoppenstein JM, Medoza CB Jr, Watne AL. Choledochoduodenal fistula due to perforating duodenal ulcer disease. Ann Surg 1971;173:145-7.

6 Neumann H, Nägel A, Bernatik T, et al. Endoscopic closure of large, spontaneous, choledochoduodenal fistula by using an over-the-scope clip. Gastrointest Endosc 2011;74:200-2.

7 Jaballah S, Sabri Y, Karim S. Choledochoduodenal fistula due to duodenal peptic ulcer. Dig Dis Sci 2001;46:2475-9.

8 Iso Y, Yoh R, Okita K, et al. Choledochoduodenal fistula: a complication of a penetrated duodenal ulcer. Hepatogastroenterology 1996;43:489-91.

9 Zhao S, Wang J, Ge J, et al. Implantation of covered self-expandable metal stent in the common bile duct for the treatment of choledochoduodenal fistula. J Clin Gastroenterol 2014;48:383-4.

10 Karincaoglu M, Yildirim B, Kantarceken B, et al. Association of peripapillary fistula with common bile duct stones and cholangitis. ANZ J Surg 2003;73:884-6.

11 Ikeda S, Okada Y. Classification of choledochoduodenal fistula diagnosed by duodenal fiberscopy and its etiological significance. Gastroenterology 1975;69:130-7.

12 Bethge N, Hintze RE. Spontaneous and iatrogenic choledochoduodenal fistula-endoscopic diagnosis and therapy. Z Gastroenterol 1988;26:704-7.

13 Hunt DR, Blumgart LH. latrogenic choledochoduodenal fistula: an unsuspected cause of post-cholecystectomy symptoms. Br J Surg 1980;67:10-13.

Copyright 2014 BMJ Publishing Group. All rights reserved. For permission to reuse any of this content visit http://group.bmj.com/group/rights-licensing/permissions.

BMJ Case Report Fellows may re-use this article for personal use and teaching without any further permission.

Become a Fellow of BMJ Case Reports today and you can:

- Submit as many cases as you like

- Enjoy fast sympathetic peer review and rapid publication of accepted articles

- Access all the published articles

- Re-use any of the published material for personal use and teaching without further permission

For information on Institutional Fellowships contact consortiasales@bmjgroup.com

Visit casereports.bmj.com for more articles like this and to become a Fellow 